\title{
Comparison of Microstructure and Hardness of an Equiatomic NiCo Alloy Produced by Two Routes.
}

\author{
C.D. Gómez-Esparza ${ }^{1}$, F.J. Baldenebro-López ${ }^{1,2}$, I. Estrada-Guel ${ }^{3}$, J.A. Baldenebro-López ${ }^{2}$, J.T. \\ Elizalde-Galindo $^{1}$, C.A. Rodríguez-González ${ }^{1}$, R. Martínez-Sánchez ${ }^{3}$. \\ ${ }^{1 .}$ Instituto de Ingeniería y Tecnología, Universidad Autónoma de Ciudad Juárez (UACJ), Av. Del \\ Charro 450 norte, 32310, Cd. Juárez, Chihuahua, México. \\ 2. Facultad de Ingeniería Mochis, Universidad Autónoma de Sinaloa. Prol. Ángel Flores y Fuente de \\ Poseidón S/N, 81223 Los Mochis, Sinaloa, México. \\ 3. Centro de Investigación en Materiales Avanzados (CIMAV), Laboratorio Nacional de Nanotecnología, \\ Miguel de Cervantes No. 120, 31136 Chihuahua, Chihuahua, México.
}

The conventional powder metallurgy (powder mixing, compacting and sintering) allows to obtain a wide variety of shapes and sizes at low production costs [1]. However, incorrect ductility and low understanding of deformation mechanism of several nanocrystalline metal alloys is still a problem in the field of high-strength materials application. Mechanical alloying is a solid-state powder processing technique useful to produce nanocrystalline materials. The conventional powder metallurgy can be modified by an additional step: mechanical alloying/mechanical milling; being possible to obtain materials with enhanced properties. In addition, milled powders present higher chemical homogeneity than casting. The microstructure obtained by the compaction and sintering route is typically porous and may damage the physical and mechanical properties of final products. The NiCo systems possess high ductility and are commonly used in applications that toughness, strength and wear resistance are required [2]. The aim of this work is to evaluate the microstructure and hardness of bulk specimens from mechanically alloyed NiCo powders produced by two different routes: sintering and electric arc melting.

Elemental powders of $\mathrm{Ni}$ (3-7 $\mu \mathrm{m}$ in diameter, $99.9 \%$ purity) and Co (44-150 $\mu \mathrm{m}, 99.8 \%)$ were used as raw materials for MA and weighted to obtain an equiatomic NiCo mixture. Hardened steel balls and milling container were used for milling and methanol was used as a process control agent. The MA was carried out in shaker mill (SPEX-8000M) for $10 \mathrm{~h}$ period. The ball-to-powder weight ratio was kept 5 to 1 for all experimentation. Subsequently, the powders were solid processed by cold compaction under a pressure of $1.5 \mathrm{GPa}$ and sintering at $1200{ }^{\circ} \mathrm{C}$ for $3 \mathrm{~h}$ under vacuum atmosphere. On the other hand, other samples were melting using an arc electric furnace under Ar atmosphere. The structural and microstructural characteristics were analyzed throw scanning electron microscopy and X-ray diffraction techniques. The hardness was evaluated by microhardness tests ( $\mu$ Vickers).

According to the XRD patterns shown in Fig. 1, the peaks corresponding to the powder alloy exhibit an evident broadening due to the reduction of grain size as a result of mechanical alloying process. There is no evidence about significant difference between the formed phases from the solid and liquid routes as the microstructural evidence showed in Fig. 2 corroborates. In the same figure is evident that as-cast sample exhibits a free-pore microstructure. However, hardness results shown in the Fig. 3 give evidence that the hardening reached in milled samples $(557 \mathrm{HV})$ remains after sintering process $(389 \mathrm{HV})$ but this property decreases drastically after the melting processing $(97 \mathrm{HV})$.

\section{References:}


[1] Indranil Lahiri and S. Bhargava, Powder Technology 189 (2009), p. 433-438.

[2] M. Zamani, A. Amadeh and S.M. Lari Baghal, Trans. Nonferrous Met. Soc. China 26 (2016), p. 484 -491 .

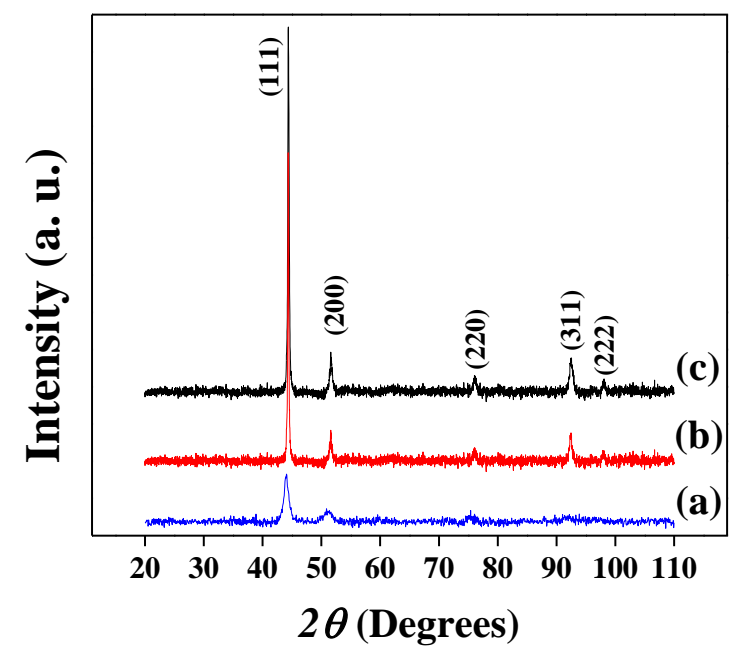

Figure 1. XRD patterns of NiCo alloy in the (a) as-milled, (b) sintered and (c) as-cast conditions.
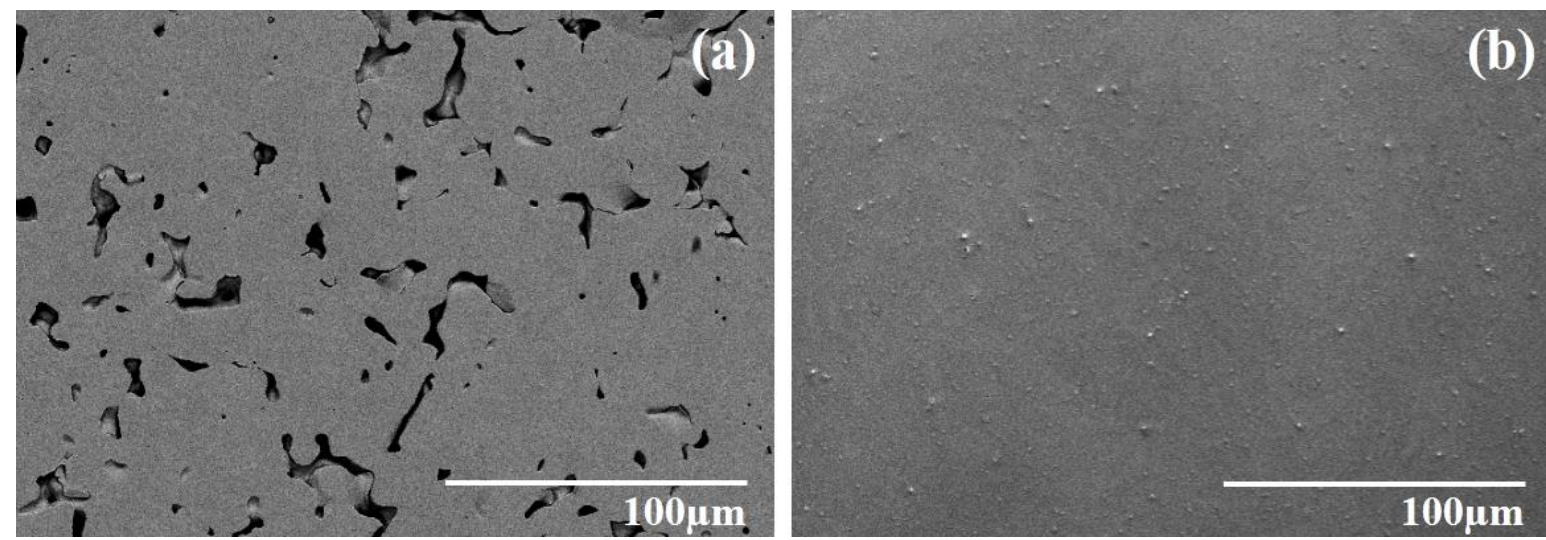

Figure 2. SEM images of the microstructure of the (a) sintered and (b) arc melted NiCo alloy. By arc melting the result is a free-porous bulk alloy.

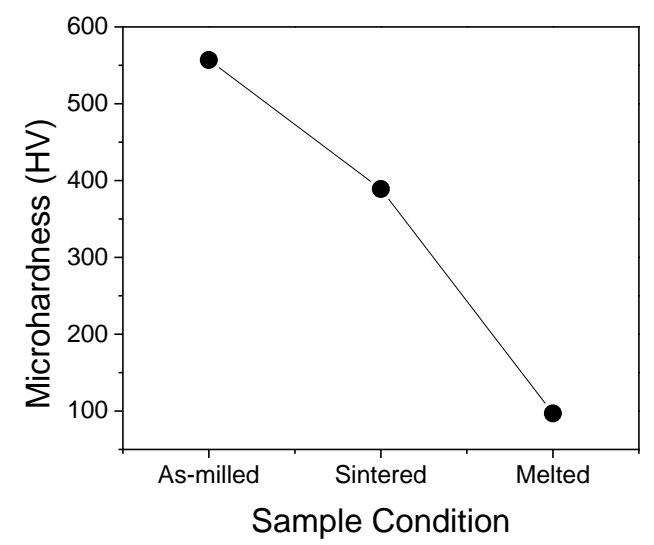

Figure 3. Microhardness Vickers results of NiCo alloy in (a) as-milled condition, (b) sintered and (c) as-cast samples. 